\title{
Peptide Bond Constituents
}

National Cancer Institute

\section{Source}

National Cancer Institute. Peptide Bond Constituents. NCI Thesaurus. Code C118427.

The amine group and carboxyl group found in adjacent amino acids that form a peptide bond. 